\title{
Decoding and Disclosure in Students-as-Partners Research: A Case Study of the Political Science Literature Review
}

Mary Rouse, Political Science, Elon University, North Carolina, United States

Julie Phillips, History, Elon University, North Carolina, United States

Rachel Mehaffey, Performing Arts, Elon University, North Carolina, United States

Susannah McGowan, King's Learning Institute, King's College London, London, UK Contact: susannah.mcgowan@kcl.ac.uk

Peter Felten, Center for Engaged Learning, Elon University, North Carolina, United States

\section{ABSTRACT}

The Decoding the Disciplines (DtD) methodology has been used by faculty to identify "bottlenecks" to student learning: disciplinary concepts or practices that prove challenging or troublesome to students. This article outlines what happened when a student-faculty partnership research team applied the DtD approach to a specific disciplinary practice in political science. The research team, led by three undergraduate students, compared how faculty and students decoded the task of writing a literature review in political science. This research yielded both insights into why the literature review is a bottleneck in political science and reflections on the practice of partnership in the Scholarship of Teaching and Learning (SoTL). Results from the interviews revealed fundamental differences in how faculty and undergraduates conduct literature reviews in this discipline, including a troubling disjuncture as students become more expert in this process. Further results about the student-faculty partnerships highlighted important tensions related to disclosure and power in conducting SoTL research.

KEYWORDS

Student partnerships, decoding the disciplines, political science, literature reviews, SoTL

Over the past decade, the Decoding the Disciplines (DtD) methodology has been used to study "bottlenecks" to student learning in a range of disciplines (e.g., Pace \& Middendorf, 2004; 
Miller-Young et al., 2015; Shopkow, Diaz, Middendorf, \& Pace, 2012; Zhu, Rehrey, Treadwell, \& Johnson, 2012). Scholars at Indiana University first developed DtD because they recognized that "the mental operations required of undergraduates differ enormously from discipline to discipline, [and] these ways of thinking are rarely presented to students explicitly" (Middendorf \& Pace, 2004, p. 3). "Decoding" or deconstructing essential disciplinary concepts yields crucial information that has the potential to positively impact learning within any discipline. While highly generative, the DtD approach involves faculty talking with fellow faculty members to explore a bottleneck as a peer-to-peer dialogue on what they want students to learn. In consultation with David Pace, one of the founders of DtD, we set out to discover what would happen if students and faculty partnered to use the DtD methodology to investigate a bottleneck to student learning, something that has never been reported in the literature.

SoTL scholars are increasingly inviting students into the research process as partners (Felten, 2013; Cook-Sather, Bovill, \& Felten, 2014; Healey, Flint, \& Harrington, 2014; Werder, Pope-Ruark, \& Verwoord, 2016), though the actual practice and ramifications of student-faculty partnerships in SoTL remain relatively underexplored (Allin, 2014). Since a fundamental purpose of DtD is to understand student learning (Diaz et al., 2008), student perspectives on disciplinary bottlenecks seem to be essential to understanding student expectations of learning in a discipline. We also believe that student research partners are particularly well positioned to explore, analyze, and interpret any potential mismatch between teacher and student perceptions of bottlenecks to learning. Because of this, student-faculty partnerships in DtD have the potential to reveal not only different perspectives on common bottlenecks but also distinct challenges and opportunities for research in the scholarship of teaching and learning.

\section{METHODOLOGY}

The literature review is a staple of scholarly writing in many disciplines, including political science (Ridley, 2008). Literature reviews require the author to synthesize the findings or methods of multiple scholars and to position one's own work in relation to the broader field (Ridley, 2008). This type of scholarly writing is an apt bottleneck to use in a decoding study because it is a common assignment in political science courses that poses challenges for many students. Indeed, Cisco (2014) found that this is a particularly frustrating assignment -a bottleneck to learning-because students often have "difficulty with the structure of the literature review" (p. 42). In the political science department in this study, students begin to write literature reviews in their second year in a research methods course and continue to do so in courses through their final year when they have to complete extensive research paper.

Our research team consisted of three undergraduate students, one faculty member, and two external faculty consultants. The three undergraduates were in their final year of university and had studied political science. The faculty member, actively engaged in student-faculty partnership research, asked these students to participate in this study because he had worked with one of them before. One of the external faculty consultants co-created the DtD process, so he advised on preparing for the interviews participated in analyzing the results. The other external partner had experience with the DtD methodology, qualitative research methodologies, and SoTL. While the students on the team led each aspect of the project except for the initial conceptualizing of a DtD partnership study, the team worked cohesively at each 
phase to induct students into the DtD methodology and to empower them to employ qualitative interviewing and analysis techniques.

This study was conducted at a mid-sized, teaching-intensive university in the United States. We received approval for our research process from the university's Institutional Review Board (human subjects research ethics board). In order to gather multiple voices from the political science department, we not only invited faculty but also students in their fourth and second years of study at the university. We focused on students at different stages in their undergraduate studies in order to complicate the "student" perspective (Goldschmidt, 2014). The undergraduates on our research team emailed an invitation to participate in the study to every second- and fourth-year political science major in the department. Five fourth-year students who had completed their political science senior seminar agreed to join. The senior seminar was their capstone or final integrative course, where each student wrote an extensive research paper, including a literature review. Three second-year students who had completed a political science research methods course also agreed to join. The research methods course serves as a core part of the program; it requires students to assemble a portfolio of researchrelated tasks including an abbreviated literature review and typically marks the first time students in this field create a literature review.

Three political science faculty members volunteered to be a part of our study. Within this group, each faculty member had recently taught either research methods or the senior seminar, although our faculty participants were not necessarily the professors who had taught the students in this study. The faculty participants included both male and female and tenured and tenure-track professors, and their teaching experience ranged from five years to more than twenty years. We refer to specific participants by their label and a number (i.e., Fourth-year \#2, Faculty \#3, etc.) throughout this paper to maintain anonymity.

The Decoding the Disciplines methodology aims to assist faculty in thinking about what they want students to learn by breaking down complex tasks into component parts which then can be readily assessed. The methodology promotes peer-faculty dialogue on disciplinary practices and an exploration of how students learn those practices, and it also prompts faculty to share what they are learning about student learning after having engaged in this process. The phases of the process include: defining the challenging bottleneck to student learning, uncovering the mental tasks associated with the bottleneck, modeling those tasks for students, embedding motivation to complete tasks, assessing those tasks, and sharing work among colleagues to disseminate practices (for an overview of DtD, see:

http://decodingthedisciplines.org/).

For the purpose of this study, we engaged in the first two phases of the DtD approach to gather perspectives on the literature review as a bottleneck and outline how each participant described the mental tasks involved in writing a literature review. The core DtD methodology is a semi-structured interview between faculty members where the interviewer prompts his or her colleague to reflect on and articulate the steps needed to navigate a specific disciplinary task which has been identified as a bottleneck to student learning. The interviewer's task is to help his or her colleague to make explicit all of the steps a disciplinary expert would take to work through the bottleneck. Middendorf and Pace (2004), for example, explain that "the task of the interviewers was to repeatedly probe beneath the surface, asking questions such as, 'Just

Rouse, M., Phillips, J., Mehaffey, R., McGowan, S., \& Felten, P. (2017) Decoding and Disclosure in Students-as-Partners Research: A Case Study of the Political Science Literature Review. International Journal for Students as Partners 1 (1) 
how are the students supposed to do that?' or, 'What does that instruction assume that students are able to do?"' Because the undergraduate students on the research team were conducting these DtD interviews, they decided to design a question protocol as a reference guide (and sought advice from the two faculty consultants in a Skype session). Even though the typical DtD process does not involve asking faculty about how they teach a bottleneck, we made the intentional decision to gather information about how faculty in our study teach the literature review so that we could explore the similarities and differences between how these faculty (a) teach students to conduct a literature review and (b) conduct a literature review in their own research.

Students on the research team conducted every interview, with one student serving as the primary interviewer and the other two acting as note-taking observers. In addition to asking each participant the same set of semi-structured interview questions, the student researchers prompted each interviewee to outline on a whiteboard his or her process of writing a literature review. Interviews were recorded to capture audio only, and the student researchers transcribed all 11 interviews. Then each student researcher separately read the transcripts, looking for salient points of each interview, before the three student researchers merged these points into categories and then themes (Corbin \& Strauss, 2008; Saldana, 2015; Creswell, 2014). Once the students consolidated their emergent themes, they invited the faculty member and two faculty consultants to analyze the transcripts by coding for these themes. Then the full research team met via Skype to discuss what each researcher had uncovered and to reflect on the process of having students take the lead on DtD interviews and analysis.

One of the main limitations of our study is its small size. Because of this limitation, we will not make conclusive claims about the political science literature review or students-aspartners in DtD research. However, we present our findings in the spirit of Kenneth Elbe's observation that "it is attention to particulars that brings any craft or art to a high degree of development" (quoted in Huber \& Hutchings, 2005, p. 36). First we will present our interview analysis, followed by a discussion of the process of engaging in student-faculty SoTL research partnerships.

\section{Decoding faculty research practices}

In the faculty interviews, the research processes revealed both the nature of the disciplinary literature and the analytical and organizational skills that faculty experts employ in literature reviews. Faculty \#1, who conducts primarily qualitative research, explained that the structure of a literature review emanates in a "radial" fashion from the topic to its surrounding issues. He further discussed the importance of context in how he begins this process, asking, "Where does this fit and what do other people have to say about it?" Once this contextual question is answered, he then determines the literature he will read and identifies the audience for his research. Faculty \#2, who focuses mostly on quantitative research, described a process of searching multiple databases for articles and then sorting those articles by themes. Faculty \#2 outlined a standardized template for both the process of conducting and the format for writing every literature review. Unlike Faculty \#1's "radial" and emergent approach, Faculty \#2 emphasized the importance of having a consistent analytical and organizational approach to the literature review. Faculty \#3, another quantitative researcher, described the literature 
review as an iterative and "creative" process of asking a question informed by theory, exploring the relevant literature, and then revising the question. Like Faculty \#1, Faculty \#3's literature review process varies depending on the context of the inquiry, but it always aims for comprehensiveness.

Although they outlined different approaches to literature reviews, all emphasized the recursive, iterative nature of the literature review process. The three faculty each recognized that undergraduates would not be able to replicate their specific expert practices when conducting a literature review. Faculty \#3, for example, remarked, "What I do is so different than what undergraduates do because I already know the literature." The most significant gap between their approach and an undergraduate approach, each concluded, emerged from their relationship with the discipline; for instance, Faculty \#1 noted that undergraduates are just beginning to learn the field of political science, but "it's different for me because I'm embedded in it."

\section{Decoding faculty teaching processes}

Despite the individual differences in faculty research practices, all three described teaching the literature review as a step-by-step process intended to build student knowledge and skills along the way; in other words, the process they teach is distinct from the "radial" or nonlinear approach they attributed to their own research practices. The two more experienced professors explained how their teaching processes evolved from the realization that students do not come to class automatically knowing how to write a literature review. Faculty \#2 recalled, "When I first started teaching as a grad student, I just didn't really get it. I figured that everyone knows what that is, so I don't need to waste time telling [them]." Having learned that this assumption was problematic, she developed a segmented teaching approach that is echoed in each faculty member's descriptions.

Faculty \#1's approach to teaching a literature involved four steps: identify a topic, synthesize material, tie concepts together, and have a conclusion to lead to another research question. This professor used sequential assignments requiring students to write a "scholarly literature essay" based on a small set of sources to practice the task of "tying concepts together." To reinforce the practice of organizing literature into themes, this professor also regularly used exam questions asking students to practice skills necessary for conducting effective literature reviews, such as analyzing arguments, variables, and conclusions within scholarly abstracts.

Faculty \#2 framed the process of teaching students to conduct a literature review as a series of steps designed to help students learn to read disciplinary research: "I tell them what to look for [in the scholarly articles] - research question, theories, the type of citations, who are they citing most frequently, what kind of method, what kind of statistical analysis, and of course you read the conclusion." This professor asks students to annotate the sources because "annotations help structure the material-because students are meant to read, annotate, and then categorize the annotation in some way related to the topic." Faculty \#2 links the annotations to the development of the structure of a literature review paper. The emphasis in this step-by-step approach is on skimming many articles and completing an annotated bibliography as an interstitial step leading to the organization of the literature into themes.

Rouse, M., Phillips, J., Mehaffey, R., McGowan, S., \& Felten, P. (2017) Decoding and Disclosure in Students-as-Partners Research: A Case Study of the Political Science Literature Review. International Journal for Students as Partners 1 (1) 
Faculty \#3 asks students in the research methods course to build a portfolio of work to help "compartmentalize each of these steps" of developing a full literature review. This "modified version" of the literature review focuses on analytical reading: "the first thing that they have to know is how to really extract every piece of information as efficiently as possible from articles, so it's really about reading articles and understanding the structure of articles." Faculty \#3 admitted this might be counterintuitive to many students who have been instructed to read deeply and now were being urged to "read a lot of stuff superficially." Skimming and scanning literature might be a common student practice, but it often is not how students have been taught to read in their prior schooling.

Despite the variations, all three faculty emphasize the importance of learning discrete skills by taking deliberate steps through the literature review process. However, the sequential steps taught in the process run counter to how the professors conduct literature reviews in their own research. There is a gap between their own recursive, immersive practice and the more structured, linear, and time-limited assignments that they give their students. While breaking down a complex task of expert practice into smaller tasks is pedagogically sensible (Collins, Brown \& Newman, 1991), our DtD interviews of undergraduates raise the possibility that this approach may unintentionally create a bottleneck for students who are learning the literature review process.

\section{Decoding student approaches to the literature review}

In interviews with undergraduate participants, the first questions posed by our student research team focused on the purpose of a literature review in political science. Both secondand fourth-year students explained the literature review as simply a way "to place their own research within a disciplinary context." Second-year student \#2, for instance, described the purpose as "[analyzing] the literature that is already out there before coming up with our own hypothesis about what [I] wanted to study." Another second-year student explained that the purpose is to "[connect] the background on the research you're doing in terms of the content to see what other people in your field are looking into, and how it relates to what's out there already on your topic." Among the second-year students, the purpose of the literature review was closely tied to knowing about existing scholarship and relating your own topic to this body of research.

Students in the fourth-year political science capstone course at the time of the interviews indicated that the purpose of the literature review is "to condense and reiterate the existing literature to lay a foundation for the rest of the paper" (Fourth-year \#4) and to "present what other scholars have already done on the subject, make it relatable so that when you do an analysis or whatever you're doing in your research, you've already presented their research" (Fourth-year \#2). Fourth-year students demonstrated an understanding of the literature review as a necessary framework for the rest of their research paper while secondyear students focused on the need to review or "know" the literature itself.

The consistency of these student responses suggests that understanding the purpose of a literature review is not a bottleneck to learning in political science, at least not for the students we interviewed. Instead, bottlenecks seemed to emerge when students attempt to apply their understanding. A gap emerged between the segmented, sequential version of a 
literature review students are often taught and the complexity of actually conducting a literature review in the discipline.

All three of the second-year students we interviewed outlined the process of writing a literature review in basic terms: find a topic, search for articles, and write. One student insisted: "It is not complex." However, when we asked them to decode this process in detail, all of the second-year students struggled to explain the approach they used. Second-year \#3, for example, could not identify any specific steps in this "simple" process:

Interviewer: When you did the [literature] review for Research Methods, what were the steps that you did, exactly?

Second-year \#3: Sure... I just wrote, kind of. I don't know... I just wrote it.

Indeed, the interviewer's probing questions about the steps each student used to conduct a literature review seemed to frustrate our second-year participants. After some back and forth, second-year \#2 flatly denied ever being taught how to do a literature review, although all three faculty in their interviews insisted this is a core component of every research methods course in the department. This student stated, "I don't think we ever really stopped and were [taught] 'This is how to write a lit review.'" During the interview, each of the second-year students described the literature review process as basic and straightforward. Yet as each interview unfolded, these students seemed to come to the realization that the process of weaving multiple scholarly articles into a cohesive analysis linked to their own research question was in fact very challenging. For the second-year participants, one bottleneck appeared to emerge when transitioning from collecting research to writing a draft literature review.

The fourth-year student participants in our decoding interviews also noted this as an important bottleneck to their learning. As one fourth-year student described:

I think the hardest part for me is condensing an argument into this sort of simplified, essentialized two sentences [and] then weaving together a narrative of several arguments, without using quotes or plagiarizing. To find a way to weave it all together to make sense, but not only just to make sense of it, but to also make sense of where my argument is going.

Other fourth-year students also acknowledged the difficulty in finding and reviewing multiple journal articles to make them relate to their topic: "making sure they all relate in some kind of understandable concrete way would be the hardest for me. That's what I really struggled with in my research methods class" (Fourth year \#5).

Despite the difficulty of the task, we found some evidence of fourth-year students moving away from the step-by-step approach to a less linear process for the literature review. Fourth-year \#1, for instance, described the process as "very much stream of consciousness, back and forth," with his reading of relevant scholarship leading him to revise his research question, which prompted him to return to the literature. Although this is comparable to how faculty describe their own expert process, Fourth-year \#1 and his peers repeatedly told interviewers that this approach is "not how you're supposed to do it, I know, but that's how I

Rouse, M., Phillips, J., Mehaffey, R., McGowan, S., \& Felten, P. (2017) Decoding and Disclosure in Students-as-Partners Research: A Case Study of the Political Science Literature Review. International Journal for Students as Partners 1 (1) 
feel comfortable writing." One of his peers described a similar process, and then labeled it "wrong" because it did not follow the neat, step-by-step script ("the right way") she was taught. This fourth-year misunderstanding of the "messy" nature of expert practice is the most troubling bottleneck that our study identified. Our interviews surfaced a disjuncture between the highly structured and orderly way students are taught to conduct literature reviews and the complex, iterative approaches that expert scholars use to carry out their work. This bottleneck ironically may lead to students becoming less confident as they become more proficient in the process of constructing a literature review in political science.

Our small study cannot justify any firm claims about this or other bottlenecks, but we believe this suggests a need for further research and for critical reflection on the ways that common pedagogical practices might effectively teach discrete skills while simultaneously (and unintentionally) undermining the potential for students to develop expert practices.

\section{Students as catalysts in decoding and SoTL research}

As a scholarly team, we are convinced that our student-faculty partnership was essential for us to identify this bottleneck. The three student researchers first pointed out the literature review as a potential bottleneck for political science students and thereby adopted a "learning position" (Takayama, 2015) within their disciplinary community to understand their own practice, the faculty members' practices, and those of their peers. The students also conducted all of our decoding interviews, gathering the evidence we analyzed together in this project. As a team, we uncovered provocative issues related to disclosure and power when students are part of a SoTL research process as both interviewers and interviewees.

\section{Decoding power dynamics}

As the literature on student-faculty partnership suggests (e.g., Cook-Sather et al., 2014), power dynamics emerged as a core issue in our study. However, the most salient tensions were those that existed between the student interviewers and their interview subjects, not those within the research team. Throughout our interviews, modes of communication varied depending on the apparent power dynamics between the interviewee and the student researchers. As student researchers, we found that interviewing faculty was a very different experience than interviewing peers. This variance shaped the interview content and process: Faculty interviews were lengthy and occasionally off-topic, our fourth-year peers spoke casually and conversationally, and the second-year students said relatively little.

We found our position as students (albeit on the verge of graduating) conducting and leading a methodologically sound interview to be a possible barrier to ascertaining the information we sought in our research. Yet, "with a partnership approach, it is in the tensions raised, and in being prepared to acknowledge, confront and work with them in new ways, where the potential for new learning, and the 'social and educational transformation' of higher education, resides" (Healey, et al., 2014, p. 56). We experienced these "tensions" in our interviews, suggesting that the identity of the decoding interviewer might inhibit disclosure or elicit different information from a person being interviewed.

Interviewees were asked to explain in great detail how he or she goes about the process of researching and writing a literature review. This was the launching point in the interview 
sequence that asked participants to write or draw their steps on a whiteboard while narrating their thought process. When we asked faculty members to answer this question, all three interviews took on the form of a lecture. Typically, in the DtD process, interviewers interject questions such as "Why do you do this?" or "Where did this step come from?" in order to elicit tasks that might otherwise be tacit. As students interviewing faculty, we found it more difficult to interject such prompts as the faculty member took on this lecturing stance. We soon recognized this format readily mimicked a traditional classroom dynamic where a professor talks and explains ideas on a whiteboard while a group of students listen quietly, taking notes.

Additionally, we noticed that faculty being interviewed by students seemed to sidestep questions that challenged their identity as a teacher or researcher. Unwillingness to disclose information might take the form of not answering the question completely, as was the case with one faculty member, who repeatedly used circuitous responses to deflect the question of breaking down the process of writing a literature review. The other two faculty participants seemed to shift into lecture mode either as a customary way of talking to a student or else to direct the conversation away from certain aspects of our reflective prompts. If these interviews had been conducted by another faculty member, as typically occurs in decoding, perhaps these professors would have been more willing to disclose research or pedagogical concerns-and perhaps they would have been more reticent on other topics.

We also discovered there was a difference between how long faculty and students took to explain their literature review process. When answering our core interview prompts, faculty took an average of six minutes to respond to the question, and they rarely acknowledged the (admittedly somewhat meek) attempts to interrupt by the student researcher. In contrast, the student interviewees' responses consisted of two minutes at the most. In terms of the DtD process, the length of response times illustrated participants' tendencies to act on habits and assumptions about power. Within the student-faculty dynamic, students often possess a comparatively low level of agency and tend to defer to experts (Bovill, Cook-Sather, Felten, Millard, \& Moore-Cherry, 2016). In our interviews with faculty, there seemed to be an expectation for us, current students at the time, to act as passive listeners rather than interviewers guiding a research process. This might explain why faculty participants chose to stick to a pattern of communication familiar to them: talking at length to dispense their expertise.

Different power dynamics occurred during the interviews with both fourth-year and second-year students. Our fourth-year participants all knew at least one of the interviewers personally. As a consequence, the interviews flowed more like conversations among people who recognized each other as equals. They were not reticent or resistant in describing the challenges and opportunities of learning literature reviews. For the second-year students, being faced with a panel of three fourth-year student interviewers produced a different dynamic. The second-year students were typically brief in their responses, perhaps due to discomfort with talking in front of a group of older students or because they lacked things to say as relative novices in the discipline. Either way, interviewing second-year students was less like a probing DtD inquiry than an invitation to consider themselves members of the political science major or as members of a disciplinary community (beyond the research methods course) through explaining their writing process (Adler-Kassner, Koshnick, \& Majewski, 2012). Although they

Rouse, M., Phillips, J., Mehaffey, R., McGowan, S., \& Felten, P. (2017) Decoding and Disclosure in Students-as-Partners Research: A Case Study of the Political Science Literature Review. International Journal for Students as Partners 1 (1) 
were sometimes apologetic or hesitant, the second-year students also gave earnest responses while engaging with our questions during the interviews. While conducting and evaluating DtD interviews (and similar SoTL research), it may be important to consider how participants will adapt their communication style given their perceived relationship to the researchers.

While we had difficulties with disclosure with faculty interviews, fourth-year students did not appear to avoid questions to the same extent. Indeed, fourth-year students readily disclosed uncertainty: "I don't think I understood what a [literature] review actually was. I know they explain it and you get books, but sometimes the concept just didn't happen" (Fourth-year \#3). With different interviewers, however, students might be more reticent to admit these struggles or gaps in their learning, especially if a faculty member in the discipline were to interview students about challenges.

When interviewing second-year students, a lack of disclosure was a component of the interviews. We suspect these undergraduates had rarely, if ever, been prompted to be explicit about their own learning processes prior to our decoding interview. This was perhaps best illustrated when we asked Second-year \#1 to write out her process for writing a literature review, and she said, "Do you want me to map it out? I mean, I can. It's not very complex." Disclosure was potentially inhibited in this case because the second-year student did not see her writing process as sophisticated enough to merit exploring deeply. Having an interview conducted by a faculty member rather than students might exacerbate this problem with second-year students, who often had a difficult time decoding their thinking and writing processes, even to fourth-year peers. Student interviewers enabled the second-year and fourth-year students to discuss key practices in their discipline despite their confusion and struggles. Indeed, we suspect the decoding interview might have been a helpful reflective experience for our student participants, particularly the second-years, because it encouraged them to articulate their learning processes in new and productive ways.

Overall, our research suggests that students welcomed the opportunity to disclose their uncertainty to undergraduate researchers, while second-year students struggled with the type of reflection the decoding process demands, having possibly never been asked to reflect on their own thinking about their studies. We theorize that if different researchers were involved in the study, their data would have looked different than ours. For instance, if faculty had conducted the interviews with fourth- and second-year students, we hypothesize students would have been less willing to admit uncertainty or truly describe their personal process (often not the exact steps taught by faculty) for constructing a literature review.

The dynamics described around disclosure and power reveal existing hierarchies within interviews that might inhibit particular members of a student-faculty partnership gathering certain kinds of information. Both partnerships and the DtD process require participating students and faculty to step into unfamiliar territory, which may prompt resistance or skepticism (Bovill et al., 2016). From our interview experience with faculty, disclosure (or lack of it) was subject to the complex power relationship that arose between students as interviewers and faculty as interview participants. In other words, the results of every DtD interview will be determined at least in part by the position of the interviewer in relation to the interviewee. Having a faculty member or an undisputed disciplinary "expert" conduct DtD interviews with 
peers will elicit a certain kind of rich information but may elide other points; having students conduct that same interview may bring other insights into view.

Our research presents only one perspective on how power dynamics effect data collection by student researchers. Our anecdotal evidence supports the hypothesis that faculty and students both have difficulty in shedding the identities they adopt in a traditional academic setting, even when the situation in question is one in which the student is meant to be viewed as a peer. In the interviews we conducted, the students conducting the interview would ideally have been viewed as members of the academic community. The fact the interviews did not play out this way suggests power dynamics between faculty and students are persistent, regardless of setting.

Power dynamics are a cultural norm, created by the identities we each adopt and how those identities contrast with the identities of other persons. In academia, these identities are typically based on experience and prestige, such as how long one has been in higher education, how many papers one has published, or what schools one attended (Coate \& Howson, 2016). When faculty interview students, the power dynamics of the relationship parallel the power dynamics inherent in an interview setting, namely that the interviewer is in charge. When faculty are interviewing other faculty, the dynamics are likely more nuanced and less stark than those between faculty and students. But when students become the researchers, the typical power dynamics are reversed: The student is now directing the interaction. Based on our limited data, both students and faculty resisted this to some extent during our interviews. We believe this is an important area for further research of SoTL partnerships. Future scholars might compare data collected from interviews conducted by students to the data collected from interviews conducted by faculty. This sort of research would allow a direct comparison between how both the results and the processes vary between the two conditions, providing insights into how student-faculty partnerships might conduct their research.

\section{CONCLUSION}

Our small study explores the possibilities of bringing student voices into the Decoding the Disciplines process, both as interviewers/researchers and as interviewees/subjects, in order to better understand disciplinary bottlenecks. This novel approach demonstrates that students can make valuable contributions to DtD and SoTL research more broadly. We believe that some of our findings emerged because our inquiry involved students interviewing peers. In particular, the confusion fourth-year students described about their "messy" and therefore "wrong" literature review process highlights an important paradox in teaching and learning. The common pedagogical processes of using small, discrete steps to teach complex tasks might help novices become more proficient in a disciplinary process; yet, these steps also might hinder student confidence as performance becomes more expert and less scripted. Balancing the cognitive demands of disciplinary work while developing confidence in those skills poses a distinct pedagogical challenge to consider within a program of study. Delving into this bottleneck with more students learning to conduct literature reviews, or other complex disciplinary techniques, is a rich area for further research.

This study also suggests the need for further exploration of how the identities of researchers and participants influence the processes and outcomes of SoTL inquiries conducted

Rouse, M., Phillips, J., Mehaffey, R., McGowan, S., \& Felten, P. (2017) Decoding and Disclosure in 11 Students-as-Partners Research: A Case Study of the Political Science Literature Review. International Journal for Students as Partners 1 (1) 
in partnership by students and faculty. Our student interviewers noted the different responses to their questions from faculty and from fourth- and second-year students. No SoTL research team will be able to eliminate power dynamics or challenges with disclosure, but careful attention to the role of identity in preparing interview protocols and analytical frameworks may make it possible to bring additional perspectives and insights into our scholarship on teaching and learning.

Before conducting the interviews contained in this research article, the university's Institutional Review Board (human subjects research ethics board) successfully reviewed and approved this study submitted by the research team.

\section{NOTES ON CONTRIBUTORS}

Mary Rouse At the time of this research, Mary was a fourth-year political science student at Elon University. After graduating in May 2015, she spent a Fulbright year in the United Kingdom obtaining her MSc. She now works as a special assistant at the Atlantic Council, a think tank in Washington, D.C.

Julie Phillips At the time of this research, Julie was a fourth-year history student at Elon University. She is currently a Juris Doctor candidate at William \& Mary Law School in Williamsburg, $V A$.

Rachel Mehaffey At the time of this research, Rachel was a fourth-year undergraduate at Elon University majoring in dance performance and choreography. Since graduation she has worked as a professional dancer, actor, and choreographer.

Susannah McGowan is a Teaching Fellow in the King's Learning Institute at King's College London. Prior to this position she worked at the University College London Arena Centre for Research-Based Education and the Center for New Designs in Learning and Scholarship at Georgetown University. Her research interests include fostering engagement in educational development, digital learning and the scholarship of teaching and learning.

Peter Felten is Assistant Provost for Teaching and Learning, Executive Director of the Center for Engaged Learning, and Professor of history. He is the co-author of books including Transforming Students: Fulfilling the Promise of Higher Education (Johns Hopkins University Press, 2014) and The Undergraduate Experience (Jossey-Bass, 2016). 


\section{REFERENCES}

Adler-Kassner, L., Majewski, J., \& Koshnick, D. (2012). The value of troublesome knowledge: Transfer and threshold concepts in writing and history. Composition Forum, 26. Retrieved from http://compositionforum.com/issue/26/troublesome-knowledge-threshold.php

Allin, L. (2014). Collaboration between staff and students in the scholarship of teaching and learning: The potential and the problems. Teaching and Learning Inquiry: The ISSOTL Journal, 2(1), 95-102.

Bovill, C., Cook-Sather, A., Felten, P., Millard, L., \& Moore-Cherry, N. (2016). Addressing potential challenges in co-creating learning and teaching: Overcoming resistance, navigating institutional norms and ensuring inclusivity in student-staff partnership. Higher Education, 71, 195-208. DOI 10.1007/s10734-015-9896-4

Bransford, J., \& Schwartz, D. (2009). It takes expertise to make expertise: Some thoughts about why and how and reflections on the themes. In K. A. Ericsson (Ed.), Development of professional expertise: Toward measurement of expert performance and design of optimal learning environments (pp. 432-448). Cambridge: Cambridge University Press.

Chi, M. (2011). Theoretical perspectives, methodological approaches, and trends in the study of expertise. In Y. Li \& G. Kaiser (Eds.), Expertise in mathematics instruction. New York: Springer.

Cisco, J. (2014). Teaching the literature review: A practical approach for college instructors. Teaching and Learning Inquiry: The ISSOTL Journal, 2(2), 41-57.

Coate, K., \& Howson, C. K. (2016). Indicators of esteem: Gender and prestige in academic work. British Journal of Sociology of Education, 37(4), 567-585.

Collins, A., Brown, J. S., \& Holum, A. (1991). Cognitive apprenticeship: Making thinking visible. American Educator, 15(3), 6-11.

Cook-Sather, A., Bovill, C., \& Felten P. (2014). Engaging students as partners in learning and teaching: A guide for faculty. San Francisco: Jossey-Bass.

Creswell, J. W. (2014). Research design: Qualitative, quantitative, and mixed methods approaches ( $4^{\text {th }}$ ed.). Thousand Oaks, CA: Sage.

Díaz, A., Middendorf, J., Pace, D., \& Shopkow, L. (2008). The history learning project: A department "decodes" its students. The Journal of American History, 94(4), 1211-1224.

Felten, P. (2013). Principles of good practice in the scholarship of teaching and learning. Teaching and Learning Inquiry: The ISSOTL Journal, 1(1), 121-125.

Goldschmidt, M. (2014). Teaching writing in the disciplines: Student perspectives on learning genre. Teaching and Learning Inquiry: The ISSOTL Journal, 2(2), 25-40.

Healey, M., Flint, A., \& Harrington, K. (2014). Engagement through partnerships: Students as partners in learning and teaching in higher education. Retrieved from: https://www.heacademy.ac.uk/sites/default/files/resources/engagement through part nership.pdf

Huber, M. T., \& Hutchings, P. (2005) The advancement of learning: Building the teaching commons. San Francisco: Jossey-Bass. 
Lave, J., \& Wenger, E. (1998). Communities of practice: Learning, meaning, and identity. Cambridge: Cambridge University Press.

Middendorf, J., Mickuté J., Saunders, T., Najar, J., Clark-Huckstep, A., Pace, . . . McGrath, N. (2015). What's feeling got to do with it? Decoding emotional bottlenecks in the history classroom. Arts \& Humanities in Higher Education, 14(2), 166-180.

Middendorf, J., \& Pace, D. (2004). Decoding the disciplines: A model for helping students learn disciplinary ways of thinking. In D. Pace \& J. Middendorf (Eds.), Decoding the disciplines: Helping students understand disciplinary ways of thinking. New directions for teaching and learning, 98 (pp. 1-12). San Francisco: Jossey-Bass.

Miller-Young, J., Dean, Y., Rathburn, M., Pettit, J., Underwood, M., Gleeson, J., . . Clayton, P. (2015). Decoding ourselves: An inquiry into faculty learning about reciprocity in servicelearning. Michigan Journal of Community Service Learning, 22(1), 32-47.

Pace, D, \& Middendorf, J. (2004). Decoding the disciplines: Helping students learn disciplinary ways of thinking. New Directions for Teaching and Learning, 98.

Ridley, D. (2008). The literature review: A step-by-step guide for students. London: Sage.

Saldaña, J. (2015). The coding manual for qualitative researchers. Los Angeles: Sage.

Shopkow, L. (2010). What "Decoding the Disciplines" has to offer "Threshold Concepts"' In J.H.F. Meyer, R. Land, \& C. Baillie (Eds.), Threshold concepts and transformational learning (pp. 317-32). Rotterdam: Sense Publications.

Shopkow, L., Diaz, A., Middendorf, J., \& Pace, D. (2012). The history learning project "decodes" a discipline: The union of research and teaching. In K. McKinney (Ed.), Scholarship of teaching and learning in and across the disciplines (pp. 93-113). Bloomington, IN: Indiana University Press.

Takayama, K. (2015). Cultivating learning cultures: Reflective habits of mind and the value of uncertainty. Keynote delivered at EuroSoTL Conference, University College Cork, Cork Ireland.

Werder, C., Pope-Ruark, R. \& Verwoord, R.(Eds) (2016). Students as co-inquirers. Teaching \& Learning Inquiry: The ISSOTL Journal, 4(2). Retrieved from http://tlijournal.com/tli/index.php/TLI/issue/archive

Zhu, C., Rehrey, G., Treadwell, B., \& Johnson, C.C. (2012). Looking back to move ahead: How students learn geologic time by predicting future environmental impacts. Journal of College Science Teaching, 41(3), 60-66. 